\title{
STRATEGIES AND SOLUTIONS TO BUILD STRONG BRANDS FOR VIETNAM COMMERCIAL BANKS
}

\author{
Nguyen Viet Lam \\ Marketing Faculty, NEU, Vietnam
}

\begin{abstract}
The purpose of this study is to find out solutions to build strong brands for Vietnam commercial banks. In order to investigate the current situation of building a strong brand for Vietnam commercial banks, in-depth interview and survey with questionnaires were used for data collection. Managers of bank were interviewed to get information about their awareness of branding and the branding strategy of the commercial banks. To the staff of the banks and clients, a survey with questionnaires was employed to get an overview of the branding in banks. The results of this research pointed out: (1) the significant achievement in strong brand building activities of Vietnam commercial bank; (2) the existing in branding of Vietnam commercial bank, especially the awareness of managers and staff about branding. From current situational analysis, this study has proposed the strategic directions and practical solutions in order to overcome the issues of branding and create the strong branding for Vietnam commercial banks in upcoming business context.
\end{abstract}

Keywords: branding, bank's brand, strong brand, brand identity

\section{Introduction}

A strong brand is the essential property of a business. The stronger brand and the greater brand value grant the company with a long-term competitive advantage. In fact, like many other businesses, Vietnam commercial banks have recently paid great attention to branding. However, market signals indicate that banks seem to focus only on building brand awareness, not on creating values for the customers. and more dauntingly is the lack of a branding strategy. Therefore, the brand power of many commercial banks in Vietnam is very limited. This has had a significant impact on the competitiveness of banks in a more and more competitive market. Therefore, this study is conducted to assess the current situation of branding in Vietnam commercial banks and propose strategic directions and solutions for building strong brands for the commercial banks.

\section{Literature Review}

According to the American Marketing Association, a brand is "a name, term, sign, symbol, or design, or a combination of them, intended to identify the goods of services of one seller or group of sellers and to differentiate them from those of competitors." (Kotler, 1997). This definition was widely used in articles relating to brand for a relatively long period of time, along with the development of marketing sector. However, many researchers propose that such definition cannot explain the roles of brands in a world with strong globalization and fierce competition. They argue that the definition of brand is quite complicated and needs to be broaden and understood in more depth. According to Aaker (1996), brand is a definite commitment about quality, service and value in a long period of time and is confirmed through the effectiveness and the satisfaction judged by customers. Brand is an image involving the cultural, emotional, unique, physical, and visual perception of a customer that associates with an organization. Kotler and Armstrong (2011) states that brand is a name that goes along with one or many factors contributing to a product line, it is used to identify the source of 
product's characteristics. Meanwhile, MarkJ.Kay (2006) believes that brand can only be deeply understood when it was considered as a specific logical structure that associates with customer's experience. According to John Murphy (1998) - President of the International Brand Consulting company, "Brand is a synthesis of all physical, aesthetic, rational and emotional elements of a product, or line of products, including the product itself, its name, logo, "look" and all expressions of the look, that collectively over time builds clearly enough in the mental framework of the customer's mind to establish a niche there ". Kotler (1997) proposed that a brand can carry 6 levels of meanings, such as attributes, benefits, values, culture, personality and user.

Brands acquire different powers and values in market. A strong brand has a high prestige. The root of building a strong brand is creating and increasing the brand equity in the market. Aaker (1991) defines brand equity as a combination of equities relating to a brand, name and symbol of a brand. Brand equity supports or reduces the values created by the products, services after the production process of a company. Those values include loyalty, recognition, quality perception, brand association and other brand equities. According to Kotler (1997), to build a strong brand, marketers must conduct some fundamental decisions below: associate or not associate the brand, the brand representative, the name of the brand, the brand strategy and the brand repositioning.

\section{Research Methods}

From the theorical framework above, the main research model including 4 stages is created to assess the strong brand building activities of commercial banks in Vietnam. In each stage, each individual bank must conduct different activities (See figure 1)

The research was carried out at 4 banks including Vietnam Joint Stock Commercial for foreign trade (Vietcombank), Vietnam Joint Stock Commercial Bank for Industry and Trade (Vietinbank), Vietnam Joint Stock Commercial Bank for Investment and Development of Vietnam (BIDV) and Lienviet Postbank (LPB).

Qualitative research methodology was used to collect data in in-depth interviews with managers of four Vietnam commercial banks to assess the perception, investment and branding practices of the banks. The sample of the study comprises of the total of 5 interviewees in the board members from each bank: one member of the management, one member of the executive board, one department leader, one branch leader and one department leader of the branch. 
Step 1: Planning brand strategy

Marketing research, identifying targeted customers, brand positioning, declaring brand mission.

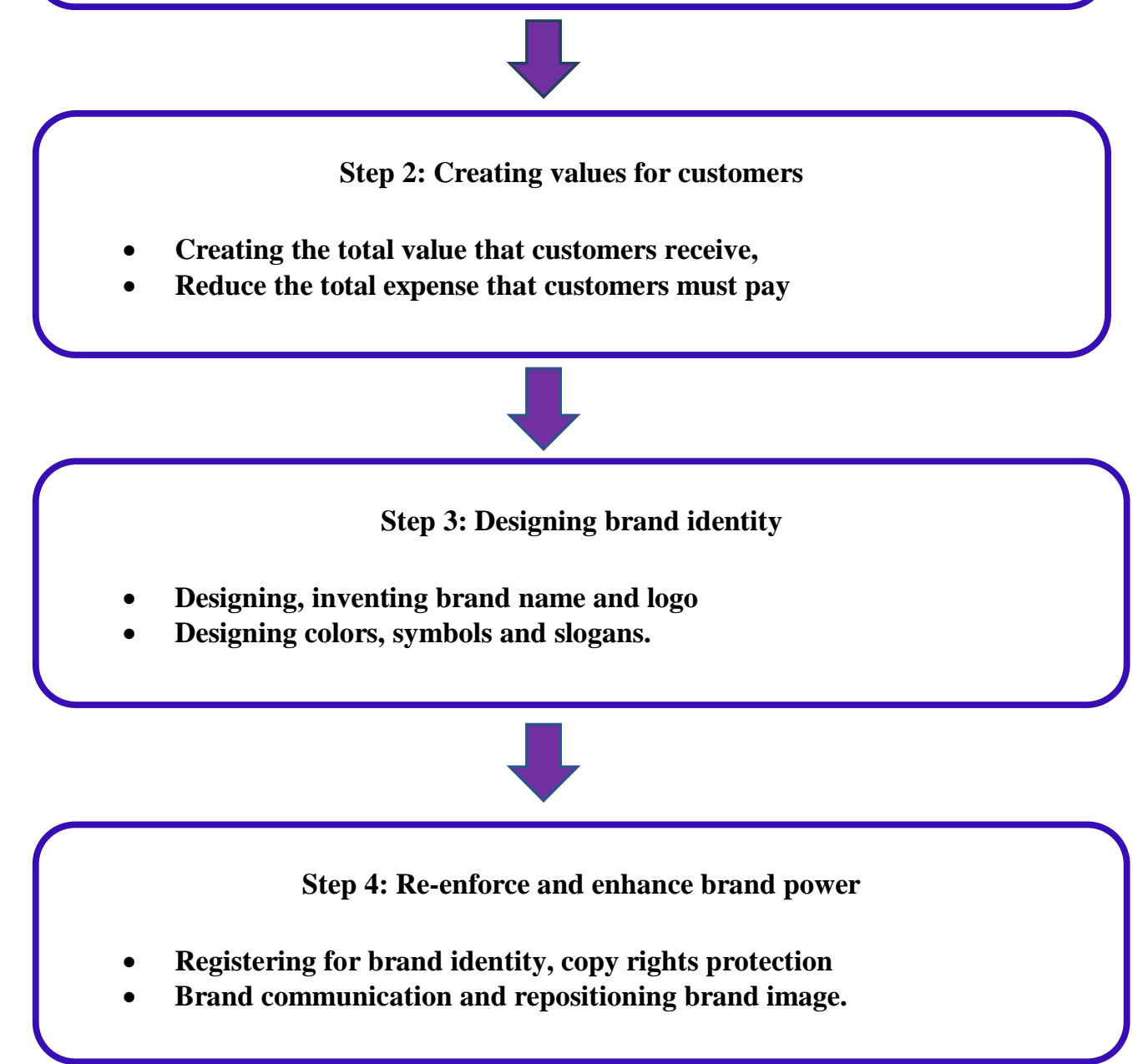

Figure 1: Model of the steps for building a strong brand

Two quantitative surveys using the questionnaires were conducted to assess the successes and limitations of branding in terms of perceptions of branding including branding awareness, investment resources on branding and the situation of branding activities of commercial banks. The first survey was carried out with a sample of 100 employees in different divisions of four banks ( 25 employees each bank). The second survey was conducted on a sample of 200 clients in 4 banks (50 clients each bank). The scale used in the questionnaires is a 5 level Likert scale. Collected data was then encrypted, inputted and processed using SPSS version 22 software.

\section{Research Results and Discussion}

\section{Achievements in building brands of Vietnam commercial banks}

First, almost all four banks are interested in branding development. In fact, from small to large scale, from newly established to long-term operated, all the commercial banks have concerned about 
branding. 100\% of interviewed managers confirmed the needs and efforts of the banks for branding investment. All interviewed customers are also aware of the brands of banks.

Second, the brand identity of many commercial banks has been developed in both width (with full equity: name, logo, slogan, etc) and depth (each element is designed with carefully developed content and meaningful implications) and have appropriate adjustments over time. All interviewed employees mentioned the brand identity of banks in order to prove the brand awareness, investment and activities.

Third, the majority of Vietnam commercial banks not only pay attention to branding development but also on other aspects, which can be seen as the submerged iceberg as well. They include the contents and core values of provided products and services from the commercial banks. These aspects can be considered as brand essences and play a decisive role in the brand value and power. The indication of branding involvement includes a wide range of activities such as products/services diversification, products/services quality enhancement, value-added services enhancement (pre, during and post sale), improving the human resources impact on customers' trust, attitude and their satisfaction.

Fourth, advertisement and branding activities have also been focused and systematically implemented. The commercial banks focused not only on external media but also on other internal branding. The following are the evaluation of the banks' internal branding activities through the staff survey (5 level Likert scale).

Table 1: Internal branding development evaluation

\begin{tabular}{|l|l|l|l|l|l|l|}
\hline No. & Criteria & VCB & Vietinbank & BIDV & LPB & Average \\
\hline 1 & $\begin{array}{l}\text { Employees and staff are fully } \\
\text { mobilized to develop branding }\end{array}$ & 4.45 & 4.18 & 4.53 & 4.00 & 4.29 \\
\hline 2 & $\begin{array}{l}\text { The bank's brand is } \\
\text { introduced to all employees } \\
\text { and staff }\end{array}$ & 4.55 & 4.53 & 4.53 & 3.90 & 4.38 \\
\hline 3 & $\begin{array}{l}\text { All employees are mobilized } \\
\text { to promote the brand }\end{array}$ & 4.45 & 4.06 & 4.29 & 4.05 & 4.21 \\
\hline 4 & $\begin{array}{l}\text { Banks are interested in } \\
\text { building corporate culture }\end{array}$ & 4.50 & 4.41 & 4.56 & 4.35 & 4.45 \\
\hline
\end{tabular}

Source: Author's survey

Fifth, brand protection is legally enforced. The interview result of bank managers revealed that all surveyed banks had conducted brand and trademark registration, not only in Vietnam but also in other countries.

Sixth, branding management regulations and implementation has been developed throughout the bank system. The surveyed banks put an enormous emphasis on internal communication to increase the awareness of employees about branding. Table 2 shows the evaluation of employees over the internal media useage. 
Table 2: Evaluation of internal media

\begin{tabular}{|l|l|l|l|l|l|l|}
\hline No. & Criteria & VCB & Vietinbank & BIDV & LPB & Average \\
\hline 1 & Internal magazines & 3.65 & 4.18 & 4.17 & 3.85 & 3.96 \\
\hline 2 & Internal network & 4.40 & 4.47 & 4.78 & 4.00 & 4.41 \\
\hline 3 & Email & 4.35 & 4.53 & 4.50 & 4.00 & 4.34 \\
\hline 4 & Direct communication & 3.95 & 4.06 & 3.83 & 2.95 & 3.70 \\
\hline 5 & Internal bulletin board & 3.55 & 3.94 & 4.11 & 3.20 & 3.70 \\
\hline
\end{tabular}

Source: Author's survey

Seven, the commercial banks have paid attention to the investment for branding activities:

- Some are promted to hire professional branding organizations and consultants. Even before designing a brand, some banks conducted market research quite elaborately and costly.

- Large banks have invested vast resources in a relatively long period of time for brand designing, development and communication. For example, to prepare for a new brand identity, Vietcombank has invested approximately 20 billion VND.

The branding investment has led to very positive results. Table 3 shows the assessment of customers towards brand equity.

Table 3: Assessment of customers toward brand equity

\begin{tabular}{|l|l|l|l|l|l|l|}
\hline No. & Criteria & VCB & Vietinbank & BIDV & LPB & Average \\
\hline 1 & Ear - catching name & 4.96 & 4.21 & 4.42 & 4.12 & 4.43 \\
\hline 2 & Eye - catching logo & 4.96 & 4.12 & 4.49 & 4.19 & 4.44 \\
\hline 3 & Meaningful slogan & 4.90 & 4.13 & 4.34 & 4.21 & 4.40 \\
\hline 4 & Beautiful logo & 4.94 & 4.27 & 4.32 & 4.19 & 4.43 \\
\hline
\end{tabular}

Source: Author's survey

This result shows that brand equity of VCB and BIDV is assessed as very good while the result of Vietinbank and Lienviet Postbank is viewed as good. Evaluation results on brand protection and brand communication also yielded the same results.

Table 4: Assessment of customers towards brand protection and communication

\begin{tabular}{|l|l|l|l|l|l|l|}
\hline No. & Criteria & VCB & Vietinbank & BIDV & LPB & Average \\
\hline 1 & $\begin{array}{l}\text { Fully - focused brand protection } \\
\text { and strengthening }\end{array}$ & 4.86 & 3.96 & 4.29 & 4.02 & 4.28 \\
\hline 2 & $\begin{array}{l}\text { Fully - conducted brand } \\
\text { communication }\end{array}$ & 4.88 & 4.43 & 4.20 & 3.98 & 4.37 \\
\hline
\end{tabular}

Source: Author's survey

Along with the efforts of the commercial banks, the assessment of customers towards brand power are as follows: 
Table 5: Assessment of customers towards brand power

\begin{tabular}{|l|l|l|l|l|l|l|}
\hline No. & Criteria & VCB & Vietinbank & BIDV & LPB & Average \\
\hline 1 & Brand power & 4.96 & 4.27 & 4.43 & 3.8 & 4.36 \\
\hline
\end{tabular}

Source: Author's survey

Except for Lienviet Postbank only has quite good brand power, the remaining banks are rated as healthy brands and VCB is seen as the strongest brand.

\section{Limitations in brand development of commercial banks}

Along with the advantages and successes, the process branding development of commercial banks in Vietnam still exists many limitations and shortcomings. These shortcomings have made the brands of most commercial banks in Vietnam still weak in comparision to the commercial banks in other regions of the world.

First of all, many aspects of strategic branding have not been properly managed. A lot of banks do not have a comprehensive and long-term strategies which rooted from the the fact that they: (1) do not have a master branding plan that is set as the goals to carry out within the banking system; (2) focus only on the second stage of the process - the stage of buidling the brand elements; (3) mainly focus on branding to customers but neglect the branding development within their employees; (4) lack longterm orientation and vision which are based on the development and changes in the domestic and foreign market. A clear brand positioning strategy has still been absent in many banks, resulting in a poor diffentiation among them. There is a lack of a clear, consistent brand image in which brands focus more on images than emotions.

Second, the banks have not got a clear brand positioning strategy: (1) the targeted customers that the banks' brand positioning aiming at is still too general (broad) (2) The corporate strategy and the brand building strategy of the competitors are still vague for a large number of the banks (3) the core values that the banks deliver to their customers has not been determined or clearly demonstrated though brand identity (4) The brand positioning methods of the banks are relatively similar and have limited distinctions.

Third, marketing researching activities supporting brand building are only conducted in some banks. The banks have not created a clear characteristic and unification for their brands and the brands hardly produce any emotional values besides visual values.

Fourth, the banks have not paid high attention to the key process of building a strong brand - the work of creating value and customer satisfaction. Most new banks only focused on the benefit of the core product or service but might forget about other benefits such as benefits from support services, benefits from communication to bank staff, spiritual benefits from the image of the bank. For example, with ladder term savings, customers will pay attention not only to interest rates but also service quality, other saving products such as insurance, deposit in one place and withdraw in other places, and so on. On the other hand, the costs of customers are not fully calculated. Besides paying the monetary cost to receive services, customers also have to pay other costs such as time, health and spirit. However, these costs are sometimes out of control for many banks. 
Fifth, brand design and development process still have many limitations. It is clearly seen in some points (1) the key process - creating customers value and satisfaction - has not been focused; (2) level of achievement in the design of different elements of the brand has been low; (3) the exploration and verification of legal status, employees' and customers' feedback on different parts of branding in decision - making process has not been taken seriously.

Sixth, the brand enhancement, development and management have not been paid enough attention. Specifically, (1) Branding development has only been focused in big cities while brand identity has not been implemented consistently throughout the system; (2) Low efficiency of communication activities due to the lack of clear objectives, primary communication tools and media (mostly advertising) and the inconsistence among tools applied; (3) Evaluation of brand advertisement effectiveness is not conducted or might be not reliable, if any was taken.

\section{Conclusion and Recommendation}

\section{Conclusion}

In order to enhance the brand power and competitive ability, commercial banks in Vietnam need to continuously successfully conduct each stage in the brand building process both in strategy and policy.

-In terms of strategy, the banks must achieve below directions and criteria:

Firstly, the banks must consider building a strong brand as a long-term process with specific strategy. Specifically, (1) The time to build a strong brand must be several years, even decades (2) Brand building process must be conducted regularly, patiently, and sustainably (3) Brand building process must acquire a clear route with suitable steps. In which, each step must be conducted with specific objectives involved in general strong brand building strategy.

Secondly, building a strong brand must be an unified process, which helps to avoid any conflicts that might ruin the whole process. To be specific, (1) Building a strong brand must be conducted at every step of building and developing a brand and these steps must be closely linked with each other (2) In each step, specific activities must also be conducted in a unified and synchronized way (3) building a strong brand must become a guideline for the whole bank including all management levels of the bank ranging from the headquarter to branches and for individual bank employees.

Thirdly, building a strong brand is a reform process consisting of adjusting, renewing and upgrading properly, timely and not only being applied for once (continuously evolving). This happens because (1) Even carefully designed brands will be undermined over time (2) Strategies, objectives, developing plans, managing methods and so on of the banks can be changed over time (3) The characteristics of brand might be gradually faded over time.

Fourth, building a strong brand is a process that has adequate investment in monetary resources, physical resources and human resources. In common sense, to achieve any results/benefits (or values) we need to invest. The results/profits get back even big or small are reasonable. The values from investment are accumulated over the years will create the true value of the brand. It cannot be denied that the total value of a brand will inevitably consists of all advertising costs, or the full value of 
continous efforts from marketing activities to the brand during the time it exists. Consequently, these true values create trust in the psychology of customers, creating perceived value from customers. Both of these values contribute to the reputation of the brand and increasing the overall value of the brand.

Finally, building and developing a strong brand must be directed toward affirming the position, rank and creating the unique style of each bank. It can be understood that through the brand, each bank needs to convey to the customer an important message that the bank is or will be at which position and which rank among commercial banks. And if the rank or position that each bank expected is also perceived by the customer, the positioning has good results and the brand power is affirmed.Some styles can be aimed at: (1) Building a unique and clear image for the brand based on product quality and professionalism of the employees to gain the favor of customers (2) Combining brand and market (3) Branding or cooperating brand.

- Regarding tactics / operations, measures should be taken includes:

Firstly, building and improving brand identity and brand image. The brand is the "soul", the prestige and image of the bank in the mind of the customers, thus even if a bank acquires full logo, name, registered intellectual property rights, laws of recognition and protection, and so on, it might not totally confirm that it has a brand. In fact, successful brands often carry emotion, personality, figuratively, and are conveyed with the right message. Therefore, when giving a plan to build and develop the bank's brand name, it is necessary to answer the following questions: (1) Do products / services that the bank provide to their targeted customers have any unique/interesting features compared to the products in the same category?; (2) If you consider the brand as a human being, what kind of personality can be determined?; (3) If the bank brand is considered as an image, what kind of image is the identity?

Secondly, promoting brand communication with a number of requirements:

(1) Must be carried out regularly and repeatedly many times and must be done in a persistent and consistent way. Some people say that promotion of branding could not be done once, although its result was amazing. Repeating communication many times to be effective is considered as a rule. Thus, since the brand is built, it must immediately be promoted to the consumer and the public, and such communication will continue throughout the brand life cycle. However, how much the frequency and scope of communication is enough? Decisions on the width of communication depend on the communication strategy of each bank and the budget of each bank.

(2) Use many different tools to promote the brand at the same time, and they must be structured in a reasonable manner, which help them to work closely together and complement each other. Theoretically, there are many different tools that can help carry out the brand promotion. However, in order to select the optimal structure of the tools or specific means of each tool, the banks must carefully consider their pros and cons, and study the characteristics of the banks' specific business sector (credit or capital mobilisation, lending to corporate clients or individual clients, and so on). When using many tools (or means) of communication, it is inevitable that these tools must be integrated closely, to ensure consistency and supplementary.

Thirdly, focusing on brand protection through media crisis management. Brands need to be protected (after registration of ownership) through legal instruments and also protected through brand owner's 
methods. As an important asset of the business, the brand needs not only to be promoted and developed, but also to be protected especially when there is a media crisis. The media crisis will undermine the value of the brand. The basic contents of media crisis management are: (1) Identifying potential hazards (2) Avoiding risks (3) Planning unexpected incidents (4) Identifying crisis (5) Crisis prevention (6) Crisis resolution (7) Media control (8) Learning from the crisis. The trend of media crisis management is that the commercial banks must focus their efforts on the preparation phase (prevention) with the calculation of the probability of a crisis and determine the damage if the crisis occurs (crisis matrix); propose solutions (modalities) to prevent and limit high risk of crisis and / or major damage.

Finally. completing the process of implementing strong branding, consisting:

(1) Having a sufficient investment in money and facilities for branding. The investment depends on the strategic goals of brand building and the financial potential of each bank. However, to build a strong brand, any bank must also meet the following requirements: (a) The investment for strong branding must be carried out regularly. (b) Investing in building strong brands at all stages of the brand building and development process including creating value for customers, building brand identity and strengthening commercial banks must be carried out. (c) The investment in the building and development of strong brands must be effective. Under current conditions of commercial banks in Vietnam, more investment is required for the first stage and the last stage because of the low investment. (d) The development and investment of strong branding should be as big as possible.

(2) Strengthening research and using market research results in branding. Information from market research can be used in the development of new products and services, in building brand identities, and in communication and branding activities.

(3) Regularly evaluating brand value. This is a very important work to affirm the core value of the brand and to judge the current powers of bank's brand. Thus, the directors of the banks can have appropriate methods to keep consolidating, building, and exploiting the value effectively.

(4) Building apparatus, human resources for brand management and hiring branding consultants. Besides financial investment, the investment in human resource and system to manage the development of branding should be concentrated. For any commercial bank, brand identity can be maintained sustainably only if it becomes the bank's culture. It only happens when the top level of management focuses on the overall branding and authorizes the maintenance duty of the brand's characteristics to a competent individual. In total, Strong brand building is an activity that requires profound expertise, generalization, complexity, and professionality, therefore, it requires outstanding staff and brand-oriented organizational structure.

\section{Recommendation for further researches:}

This study only focuses on popular banks of Vietnam's commercial banking system, in which the respondents are mainly joint-stock commercial banks originating from state-owned commercial banks. In order to generalize the research results for entire Vietnam commercial banking system, the scope of the sample needs to be further expanded in subsequent studies. 


\section{References}

Aaker D. A (1991). Managing brand Equity. New York. NY: The Free Press.

aaker D.A. (1996). Building strong brands. The free Press.

Jonhn Murphy. What is branding. Brands. The new weath creators. New York. University Press.1998.

MarkJ.Kay (2006). Strong Brand and Corporate Brand. European Journal of Marketing. Vol 40. No.7/8.2006.Pages 742-760.

Philip Kotler \& Amstrong Gary (2011). Principles of marketing. Prentice Halll. 14th Edition.

Philip Kotler (1997). Marketing management. Prentice Halll. $9^{\text {th }}$ Edition.

VCB, BIDV,Vietinbank, Eximbank. Annual report (2012-2016). 